\title{
UTILIZATION OF BIOGEOMETRY IN RESHAPING URBAN ENERGY QUALITIES
}

\author{
Ahmed Wafik ${ }^{1 *}$,Ahmed Abdin ${ }^{2}$, Ibrahim Karim ${ }^{3}$ \\ ${ }^{1}$ Principal at Ahmed Wafik Designs, Adjunct Professor, St. John's University, New York, USA. \\ ${ }^{2}$ Professor of Architecture and Environmental Control, Faculty of Engineering, University, Cairo, Egypt. \\ ${ }^{3}$ Chairman of the BioGeometry Consulting Ltd, Cairo, Egypt. \\ *Corresponding Author E-mail: awafik@ahmedwafik.com
}

Received :5 Dec. 2021 Accepted:25 Dec. 2021

\begin{abstract}
Recent research and investigations in the quality of modern urban environment have indiscriminately proved that the urban ambiance is glutted by a plethora of electromagnetic fields and radiation (EMF/R) emanated from both man-generated and natural sources. Findings of other research in the areas of medicine and public health indicate for correlations between intensity of the above-mentioned fields and diseases, physiological disorders, mental and psychological disorders. The paper introduces a new approach of better understanding and regulating influences of - and interactions between - ambient urban energy fields and human physical and psychological wellbeing. It highlights the need for sensitive correlation of architecture and urban design with physics principles, by focusing on a micro level, in which both, the physical/visible and invisible energy fields - and their interactions - are considered within an integrated paradigm, eventually to secure more safe and healthy environment. This approach could enhance developing a wide range of design tools that well address maintaining effective balance between new technologies utility and their harmful side effects. The paper's goal is to provide a guideline for balancing energy fields of urban spaces, through new applications corresponding urban design techniques based on the science of BioGeometry.
\end{abstract}

KEYWORDS: Electromagnetic Fields and Radiation, Earth energies, Geopathic stress, energy fields, urban design, architecture, BioGeometry, health impact

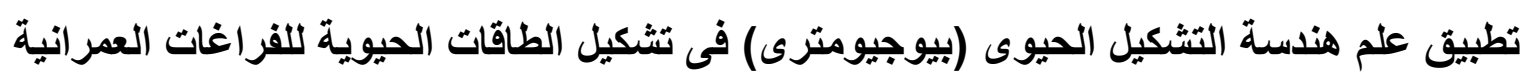




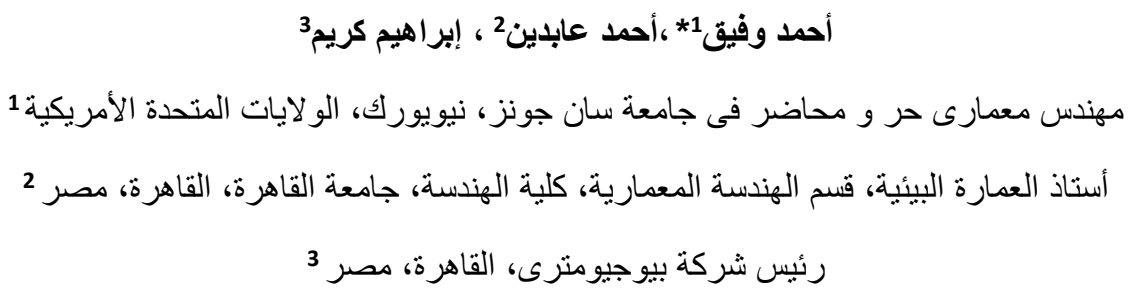

E-mail: awafik@ahmedwafik.com :البريد الاليكتروني للباحث الرئيسى"*

الملخص

أثتتت الأبحاث العلمية في مجال البيئة العمر انية على أن المجال الحضري مُحاط بمجالات كهرومغناطيسية متعددة منبعثة من مصادر

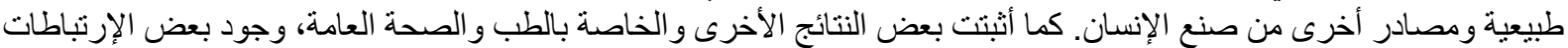

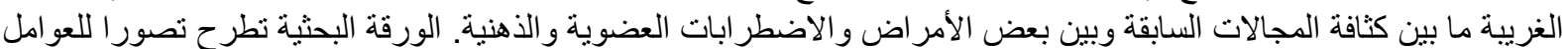

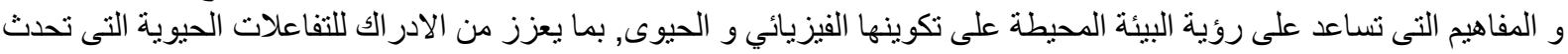

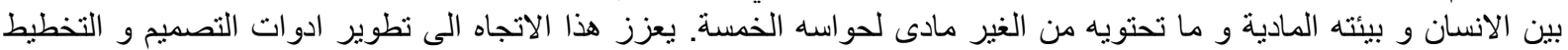

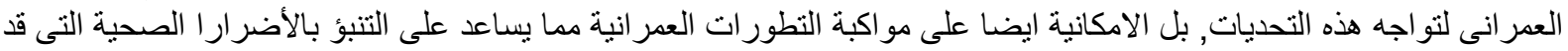

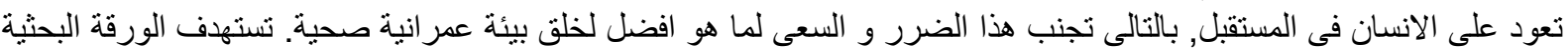

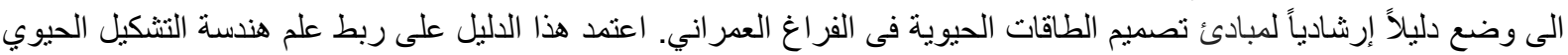

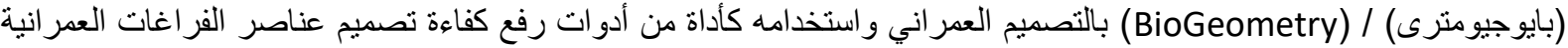

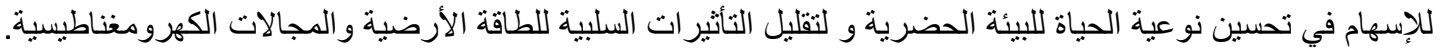

الكلمات المفتاحية : الطاقة الكهرومغناطيسية، الطاقات الحيوية، اجهادات الطاقات الأرضية، التصميم المعمارى و العمر انى، الصحة العامة

\section{INTRODUCTION}

Modern technologies advancement in the last 30 years have added many artificial electromagnetic waves intensively in all our living spaces, which is emanated from sources such as cell phone towers antennas of wireless communications, power generation stations and transmission lines, broadcasting stations, radars, cell phones, Wi-Fi systems and similar power and communication systems [1]. Studies are continuously confirming the electromagnetic waves of modern technology have a lot of harmful effects on humans, animals and plants [1123]. Since electromagnetism is one of the four universal forces that form matter and energy additional to the weak force, strong force and gravitational force [2], then the human body should be looked at as an electromagnetic entity. Here comes the critical need to deeply rethink about the type of environment we live in, materials that our homes and buildings are built from, spaces that confine our daily life, technologies that we use, and even the people we interact with. It is eminently critical now to perceive these aspects as fields and waves with different qualities or frequencies, not only as solid matter. Eventually, the human body, also, comprises waves and electromagnetic fields that are in a continuous interaction - of different types and intensities - with surrounding environment.

The paper provides specific contribution to current efforts addressing electromagnetic fields/radiations (EMF/R) phenomena in our urban environment. The first is the artificial electromagnetic forces emanated by modern technology sources, and the second is 
electromagnetic forces that are caused by different natural and geographical sources. Both have been associated to the cause of various physiological and psychological health disorders including cancer illnesses. The paper final product represents a practical guideline to minimize and offset the negative impacts of the two phenomena and ameliorate the overall quality of urban spaces. This is attained through wide and diverse arrangements, extending from preventive design measures and criteria to further attuning and treatment measures.

\section{Energy Fields, Electromagnetism \& Human Interactions}

The human body, the surrounding environment and the whole universe are made from physical elements that occupy space and mass. Zooming into the compositions of any physical element reveals its internal sequential composition of micro particles. The mass and mechanism of an atom relies on micro particles such as electrons and a nucleus [2]. The mass of these particles represents only $1 \%$ of total atom's size, while the rest is empty space. This applies to the whole physical world as perceived by our five senses. However, this empty space is

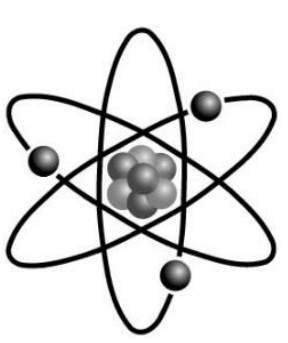

Figure-1: Electrons in a nucleus fill $1 \%$ of the atom's size. $99 \%$ is empty space that's filled with motion.

Source: www.universetoday.com teeming with vibrant motions of electrons, emitting wide range of energy fields and forces on different micro scales, sometimes referred as the Electron Cloud [3].

Electrons behave as a wave and a mass. Einstein theory of relatively ( $E=m c 2)$ confirms that mass and energy are two sides of one coin. String theory illustrates that all fundamental particles such as electrons are composed of a vibrating strings [2]. The outcome is that matter in reality is a wave, energy, or a vibration state, that encompass many and different energy fields, that are eventually perceived as a physical state, because of the limits of human senses. Looking at architecture and the built environment from that perspective opens a new understanding to how we should shape our spaces and urban environment.

Electromagnetism is a major force of the universe creation and represents not only a generative process within the fundamentals of matter, but also within the biological functioning of all living Organisms. It emanates from electrons motion; it exists from the core of earth and the poles, as well in human body nervous system, heart and brain, and in any

living cell [2].

\section{Electromagnetism of Modern Technology in the Urban Environment}

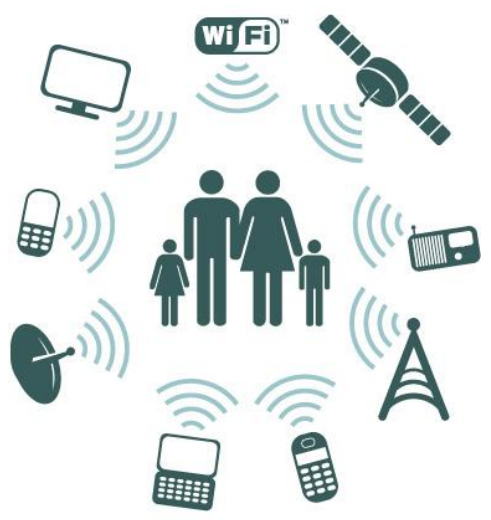


Electricity represents today - within a wider spectrum of energy forms - the main driving force of cities life, growth and prosperity. Generally it is generated of power plants, then transformed through high voltage, power lines and the distributed throughout the city's networks, to eventually feed every building, factory, and facility. Comprehending the profusion of electromagnetic fields generated by electricity flows in these expansive systems and networks that are inter meshed with every part of the urban fabric clarifies that bodies of city dwellers are almost immersed in an intensive electromagnetic zone. This is further exasperated by new wireless technologies that are increasingly expanded in the modern era [4]. Our bodies are exposed intensively 24

Figure-2: Sources of Electromagnetic field/radiation (Power lines, cell phone towers, satellites, computers, cell phones, radio, WiFi) hours a day, therefore and electromagnetic waves penetrate and interact with physiological systems of all living organisms.

World Health Organization declared that "Electromagnetic fields of all frequencies represent one of the most common and fastest growing environmental influences". All population around the globe today are exposed to varying degrees of EMF, and this is expected to increase as technology advances across different industries [4].

Sources that generate electromagnetic fields/radiations (EMF/EMR) in cities are numerous such as high voltage power-lines/station, underground/distributing power-lines, transformers, mobile masts antennas, and radars. The same applies on living and working spaces where other array of micro sources exist like home electric wiring, electric appliances, Wi-Fi, cell phones, and any electric power or wireless devices [5,6].

The intensity and range of emitted electromagnetic fields from electric cables are correlated to voltage and current intensity. As for electromagnetic radiation related to wireless technology, their range and intensity relates on antenna and the frequency radiated. The frequencies used by different sources found in the city spaces such as mobile antennas masts, broadcast towers, radars, Wi-Fi and cell phones, range between $3 \mathrm{KHz}$ and $300 \mathrm{GHz}$, where $1 \mathrm{KHz}=1000 \mathrm{wave} / \mathrm{sec}$, $1 \mathrm{MHz}=1,000,000 \mathrm{wave} / \mathrm{sec}$, and $1 \mathrm{GHz}=1,000,000,000 \mathrm{wave} / \mathrm{sec}[7,8]$.

Since electricity and the wireless technology have started to be a basic and prominent feature in human daily life, biophysicists started to be concerned of impact of these artificial waves on environment and human body, considering the fact that human heart pulses, nervous system and brain functioning substantially rely on electric pulses and frequencies, and that cells of any living organism use oscillating electromagnetic fields for their vital functions. Cells have receptors to receive and send information to and from the brain, other cells and other parts of the body [9]. If these electromagnetic frequencies in the body are impacted, distorted and disrupted, correlative sicknesses can occur. However, examining, verifying and proving the evidence of direct correlation between diverse and variable exposure and pathological indications are extremely difficult. Ignoring some clear indications or available evidences anywhere has always been the easiest and convenient approach adopted by both of public and private sectors.

This denial is based on the fact that these waves are non-ionizing, so they do not imply direct or quick effect on the human tissues. In addition, the human body always tries to fight false 
signals from the surrounding environment to keep its balanced performance of its vital functions. However, prudent cognizance and interpretation of wide scope and diverse indications clearly point to a conclusion that continuous distortion of the body's internal electric signaling system, on a daily basis, for long periods, will trigger, sooner or later, distortions and imbalances, that will be, eventually, manifested in any minor or major health problems, differentiated by age groups, as children are highly prone to higher impact levels [10]. Health issues are constantly increasing globally.

In the last 20 years, large amount of researches were conducted to study how non-ionizing electromagnetic waves affects the human body. Biological and psychological effects in humans, animals and plants have been verified and documented. Other studies have strongly traced and linked electromagnetic sources, such as high voltage power-lines, mobile antennas and radars, the evidence and rise of a lot of health problems including cancer illnesses.

The findings of some studies on non-ionizing EMF/EMR could be summarized as follows:

Increase in rate of breast cancer in women, leukemia and brain tumors in children who lives close to high voltage power-lines [11, 12]. / High rate of cancer illness among teachers working in a school that have high amount of EMF/EMR in their interior spaces [13]. / Genetic effects and DNA damage in rats brain cells after being exposed to low EMR for only 24hrs [14]. I Leakage of calcium ions from brain cells of newly hatched chicks after exposure to $16 \mathrm{~Hz}$ [15]. / Living or working close to mobile antennas lead to symptoms of muscle fatigue, headaches, dizziness, sleep disruption, depression, and lack of concentration [16]. / Reduction in the reproduction capacity and miscarriage among different animals after exposure to low EMR and being close to mobile antennas [17]. / EMF-EMR, especially of mobile antennas reduces birds' densities in urban spaces [18]. / Increased levels of adrenaline, higher heart rate and blood pressure in animals following exposure to the same amount of frequencies found in urban spaces from mobile masts and broadcast towers [12]. / Shortage of growth, increase in resin production, changes in mRNA and stress reaction in the ultra structure of trees and plants after exposure to low EMR [19, 20]. / Radiation of cell phones penetrates 2 inches in the human brain of an adult, and 4 inches in the brain of babies and children (Due to their thinner and smaller bones) [21]. / The use of cell phones for 2000 cumulative hours raises the risk of brain tumor by $240 \%$ [22]. / The radiation of cell phones affect men's semen quality by decreasing motility and sperm count [23]. / Children that use cell phones have higher risk of having poor memory, poor attention, increased fatigue, and problems of learning and behavior [23]. I Cancer cells grow 24 times faster when exposed to EMF/EMR [12].

\section{Electromagnetism of the Natural Environment}

Urban spaces have another influencing electromagnetic source that comes from the natural environment through different energy emissions of the earth surface [25, 26]. The electromagnetic features and frequencies of these energy patterns are quite different from those generated by all technological systems, as they have very micro vibration intensity. Latest studies in this area assumed that the natural aspects behind these energy patterns could be piezoelectricity (compression of quartz crystal cells on the earth surface) or longitudinal scalar waves (exists along electromagnetic waves), or also electromagnetic fields that are generated 
from underground water streams (speed flow of some specific metallic ions/particles and their concentration) [25]. Different studies clarified that these energy patterns are part of the ecological system and they contribute in sustaining natural life cycles. However, some of these patterns do not align with the human biological and electromagnetic systems. They can distort different electric signals of the body functions and suppress the immune system, leading to different health problems [26,27].

Some energy patterns depicted by geologists and earth scientists are spread all over the earth surface in a geometrical order, forming global energy grids. The very well known among them are Hartmann, Curry, and Benker grids, named after scientists discovered them (Dr.Ernst Hartman, Dr.Manfred Curry, and Anton Benker) [27]. These energy grids emanates vertically from the earth's surface like structure of radioactive walls. Each grid consist of positively and negatively charged energy lines. If one energy line is positively charged, the following parallel one is negatively charged and so on. They penetrate any material or field and can be detected on any height. They comprise nodes of higher radiation intensity when two energy lines of the same charge intersect, and the more intersecting lines at one spot or area magnify radiation intensity [28]. Underground water streams generate different qualities of electromagnetic radiation above the earth surface. The radiation intensity depends more on the width of the stream, water velocity, stream winding pattern (angles of streamline deviation) and water minerals concentration. The effect is even more intense at the spots where the flow of water strongly changes its direction [27, 29, 30].

The highly radiating spots usually feature intersection of several energy patterns. The radiation, being harmful or beneficial to human body is highly related to angles of intersection between different grid patterns. The harmful zones are usually called Geopathic Stress, which means earth suffering or disease, originated from two Latin words Geo and Pathos. The beneficial zones are usually called Power spots or Sacred spots [27].

The health concerns related to Geopathic stress (GS) areas are not related to short term exposures, they are rather related to having our homes, apartments or sleeping location above these areas, especially on the long term. Different studies showed that health problems related to GS take place when someone's sleeping location is on a GS zone for few years, in which the human body is suppressed from the ability to balance its own system for a long period, and even linked to cause cancer illnesses [27].

The findings of some studies on Geopathic Stress could be summarized as follows:

Human body stress effects (measured by GDV) found on 52 persons after being located on a GS zone for 15 minutes. No stresses found in neutral zones. / Linked to certain types of cancers and diseases. / Linked to having an influence on animals, plants, fungi and bacteria, and some malfunctions and illnesses of the human body. / Certain type of plants and trees thrive in GS zones such as (asparagus, oak, plum and peach), while some don't, such as (cucumber, celery, onion, apple, pear and beech) [25, 29-35] . 
On the other hand, earth energy grid lines are also found with positive health impact, namely referred as "Power Spots" (PS). These spots are known for their ability to reinforce the human health, and enhance healing process [27]. However, scientific data collected about the effect of power spots on living beings is limited in comparison to GS. Historical documentations from different fields
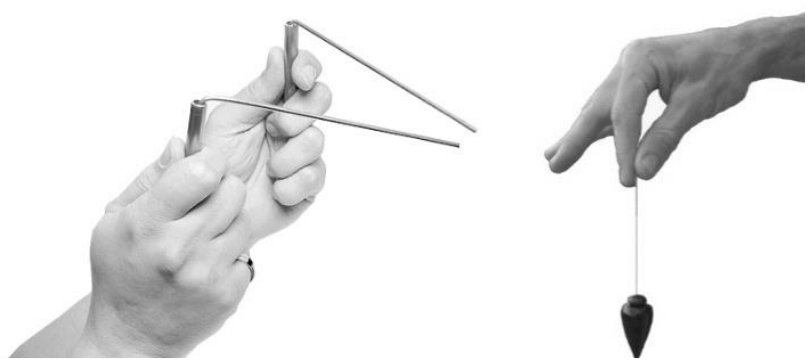

Figure-3: Radiesthesia measuring technique using L-rods

Source: www.kooma.co.uk

clarify that in ancient time, power spots played a major role in human survival, life functions, and planning towns and cities. By traditional - experience based - knowledge - many decisions were based on connecting and locating in power spots and evasion of GS. It is strongly believed that the use of megalith stones by ancient people (found in most historical ages as Dolmens \& Menhirs) [36], like other geometrical shapes, such as "Obelisk" of ancient Egypt) was mainly for marking power spots. The use of specific types of stones that weighted hundreds of tons was possibly for magnifying and amplifying the energy qualities of power spots $[3,37]$.

Detection of natural energy patterns and grid lines depend on an ancient science called Radiesthesia, a method that has been practiced for thousands of years - and still - for many different purposes around the world [38]. Innovation of technological devices that can accurately sense the wide spectrum of these micro vibrations in the environment is still developing. Radiestheisa depend on hand tools that a person hold, which becomes fixed at one side, and the other side left sensitive to be easily influenced by any weak forces related to energy fields (Figure-3). The mechanism of measuring depends mainly upon the senses of a person with good experience who can detect the micro vibrations of energy fields, as they transmitted (magnified) to his nervous system, through the hand tool. The polarity of which the movement goes, clarify whether the detected energy is harmful or beneficial, and the amplitude of the movement clarifies the intensity of that energy. The most popular radiesthesia tools among practitioners are (pendulums, L-rods, and V-rods) [38].

During the 18th century, a professor of physics from the Royal College of Science in Ireland, named Sir William F. Barrett, was the first to prove that Radiesthesia is based on electromagnetic waves. This was further approved in England through experiments conducted by J. Cecil Maby and T. Bedford Franklin, as well in Egypt by Dr. Solcol W Tromp, a professor of geology at Fouad I University (Currently Cairo University) [39]. 
The American military during Vietnam War used Radiesthesia to detect mines and explosive objects. Radiesthesia have also contributed in maintaining industrial needs for some businesses, and a current water company based in UK revealed using it as one of their methods to detect locations of water leaking in their pipes network [40-43].

One of the interesting techniques of Radiesthesia when detecting/measuring earth energies and GS, is using a map. The space satellites that take images for the earth surface, such of Google Earth software, captures a real visual image for the physical and visible surface, but in the same time, it captures differentiated reflections of invisible radiations and energy fields, which allows radiesthesia professional/practitioner to sense them from such images. However, measuring from images should never substitute measuring on site. It should be complementary - and mutually confirmative - with field investigations [3].

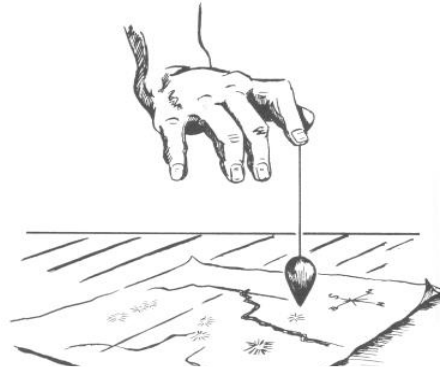

Figure-4: Locating earth energy on maps using Radiesthesia measuring technique.

Radiestheisa has always been a very useful detecting method in ancient times, however, combined with lack of understanding of its scientific base of how it works, which always created skepticism about it. Today, with major scientific advancement in electromagnetism and human biology and pathology, it is well acknowledged that radiesthesia measuring techniques are simply governed by electromagnetic waves.

\section{The Science of BioGeometry}

During the last decade, a new science called BioGeometry has started to show promising indications of successful conduct and practices of its undertaking of two studies conducted in Switzerland between 2002 and 2005, by the science founder, Dr. Ibrahim karim, an Egyptian architect and scientist [3]. In 2002, in the town of Hemberg, Switzerland, the Swisscom telecom company installed a cell phone antenna station. Following that, severe health problems and other negative symptoms (sleeping disorder, headache and more) were detected and traced. The residents were used to live in a natural and virgin environment. Both timing and spatial proximity indicated a link between pathological symptoms and the newly installed antenna. Furthermore, residents reported that some plants are no longer thriving, and some types of birds disappeared. This became a public issue was announced in the news and media. This created a lot of pressure on the telecom company and the government so they can resolve this issue. Dr. Karim offered a technical approach based on Biogeometry. The proposed solution included placing specific designed BioGeometrical shapes in the surrounding of the cell antenna and inside some of the residents' houses, particularly the residents that were strongly affected (Figure-5). In a very short period of a couple of days, almost all the residents reported to have been sleeping better and and over time, their health problems were vanishing gradually. It was evidently clear that this technical approach successfully offset harmful electromagnetic fields generated by the antenna. In the town of Hirshberg, similar BioGeometrical solutions were implemented in 2005. Results were similarly successful in countervailing harmful EMFs [44, 45]. 

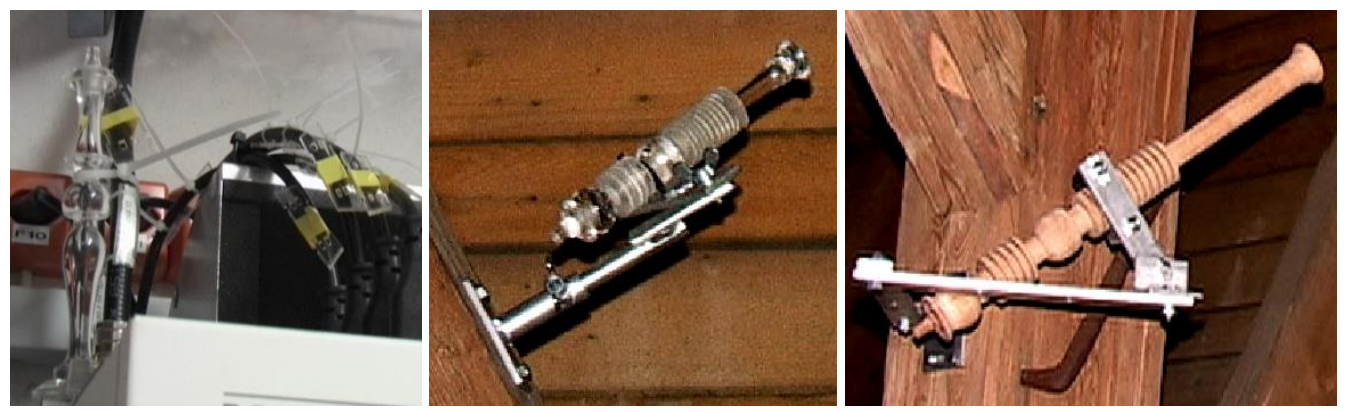

Figure-5: The BioGeometrical shapes used and placed by the cell antenna in Hemberg.

The findings of some studies using BioGeometry:

- Reduced the harmful health effects of cell phone towers and electromagnetic fields $[3,44$, 45].

- Reduced the harmful health effects of Wifi on brain function and structure [46].

- Protected against indoor pollutants from building materials [47].

- Caused a 90\% normalization of enzyme levels in Hepatitis-C patients in just 2 weeks, and lead to a large number of the patients to be totally free from viruses only after 6 months $[48,49]$.

- Improved the concentration abilities and behavior in children with ADHD (Attention Deficit Hyperactivity Disorder) [50].

- Improved the electrical function of the human body organs [48, 51].

- Reduced the stressful levels in the human body [48].

- Improved crop yields without the use of pesticides or herbicides [48, 52].

- Enabled healthy sweet potatoes to grow which were irrigated only with sea water-without the salt removed [49, 52].

- Improved the growth of chicken by $25 \%$ without using tranquilizers, hormones, vaccination or any type of chemicals $[48,49]$.

- Created healthy water internal structure, reflected by Dr. Masaru Emoto water crystals studies $[49,53]$.

Since that any physical element in reality is composed of thawing waves, then the balancing state is a product of a specific wave or frequency. BioGeometry - ultimately -seeks to engender a wave that would have a fundamental balancing quality or effect, and can be generated from configurations of different shapes, based on their proportions, angles, and dimensions. Successful attempts have lead to identify and generate this vibration wave (having a balancing quality), which was named BG3 [3]. Design criteria and methods to obtain BG3 energy quality was developed and successful advances in practices are ongoing. Shapes designed according to 
these criteria and methods have substantially contributed - in many cases and experiments to reinforce and enhance human biological systems to reach their balancing states and lead to healthier physical, mental, and emotional conditions [3].

The BG3 energy quality was originally discovered from natural energy sources, previously referred as "Power spots". BioGeometry advances succeeded in generating the same energy quality through specially designed shapes, without being physically linked to a power spot. BioGeometry has 9 design methods referred as the Nine Pillars of the BioGeometry Design Language, they are:

Qualitative Harmonics - Motion in Design - Design Principles - Qualitative Global Scaling System - Earth Energy Design - Sky Linked Design - Archetypal Design Codes - Material Energy Quality Balancing - BioSignatures [3].

Some of these design methods are sophisticated and require experience with Biogeometry applications. However, six of them are directly associated with design proportions, volume, dimension and scale, utilized in designing any physical shape. Implementing these design methods in architecture and urban design projects could lead to generation of extensive BG3 energy quality on the whole urban fabric, both in public and private spaces, eventually contributing to sustaining very positive impacts on human health, wellbeing of living organisms, quality of life, and overall environmental conditions.

\section{METHODOLOGY FOR PLANNING AND DESIGNING SAFE URBAN ENVIRONMENT}

This section aims to develop preliminary guidelines/checklist for architects, urban designers and planners to well integrate the issues of energy fields in their design decisions, and eventually produce plans and designs that are compatible - and effectively interacting - with different energy fields in the urban environment, maximizing their positives and minimizing their negatives. The ultimate goal is more healthy population, sound environment and better quality of life.

Prior any urban planning or design process, a set of data should be collected, documenting different environmental conditions of study site, locale and region, as an introductory step of assessing energy quality. The main focus is to detect and identify the natural and artificial electromagnetic fields and their sources. Mapping, assessing and evaluating the intensity of each source and its related extended fields could be eventually accumulated in an integrated spatial analysis of energy fields. This integrated analysis leads to producing a kind of master plan that compile different recommendations to the planner or designer to well accommodate with both useful and harmful EMF/EMR. It serves as a decision support guideline. It may include evading assigning any kind of land use to a specific area (harmful EMF/EMR), or limiting its use to specific land use (park area rather than housing, to reduce sustained exposure), or assigning specific uses (recreational and social spaces) to distinctively positive zone. This extend to - on purpose - shaping and attuning dimensions, volumes, landscaping, and greening of urban spaces to adjust the distorted energy qualities and generate a positive 
impact, rather than a negative one. Figure 6 shows a guideline for the data collection and design process for a project.

Artificial EQ

(High voltage \& Distributing power lines - Mobile masts antennas Broadcast towers - Radars)

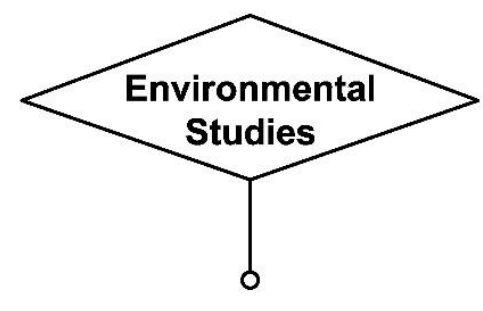

Detection ----- (Geopathic Stress - Underground

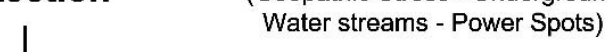

\section{Natural EQ}

Water streams - Power Spots)

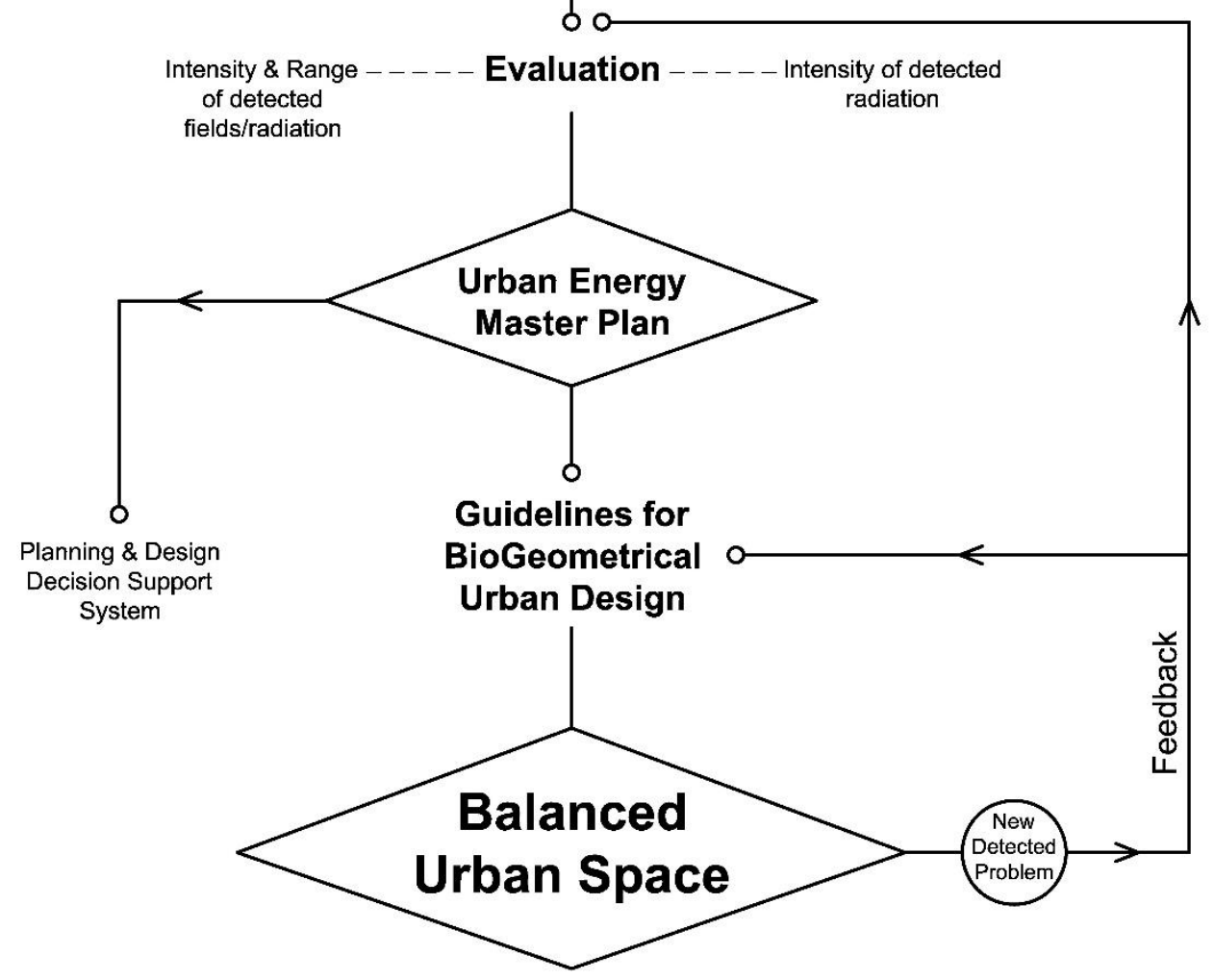

Figure-6: Proposed guideline for designing urban spaces

\section{ENVIRONMENTAL STUDIES}

\subsection{Detection}


Natural sources (Requires radiesthesia practitioner knowledgeable about earth energies):

Assessment qualities of natural energy fields should give the highest priority detection of geopathic stress (GS) zones and underground water streams, as they hold most harmful energy fields of energy fields. The used radesthesia tool is a choice of the practitioner, but it is recommended to use the BioGeometry measuring tools including the IK pendulum and BG16 pendulum that were design by Dr. Ibrahim Karim (Figure-7).
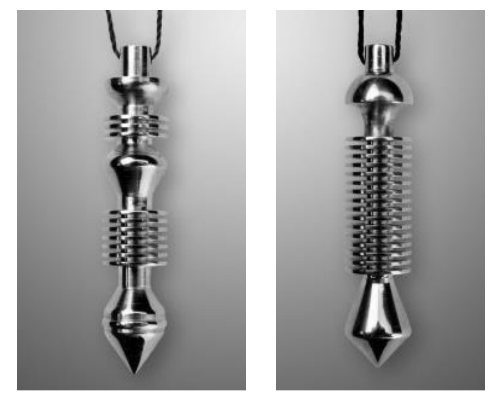

Figure-7: IK pendulum (left), BG16 pendulum (right)

The second detection priority is to seek

Source: www.todesignwellbeing.com

beneficial energy fields that can be found naturally in any power spot (PS). They can be detected using BG16 pendulum, which is designed to resonate with the BG3 energy quality. On the scale of architecture or basically small sites/spaces, the designer could further consider an elaborated design applications providing a coherent inter-linkage between the energy systems of the space and the newly designed structures, by detecting global energy patterns such as Hartmann, Curry, and Benker, using special compatible measuring tool for each one. Figure 8 illustrates marking up on a site survey the location of the detected GS areas, and different grid energy patterns.
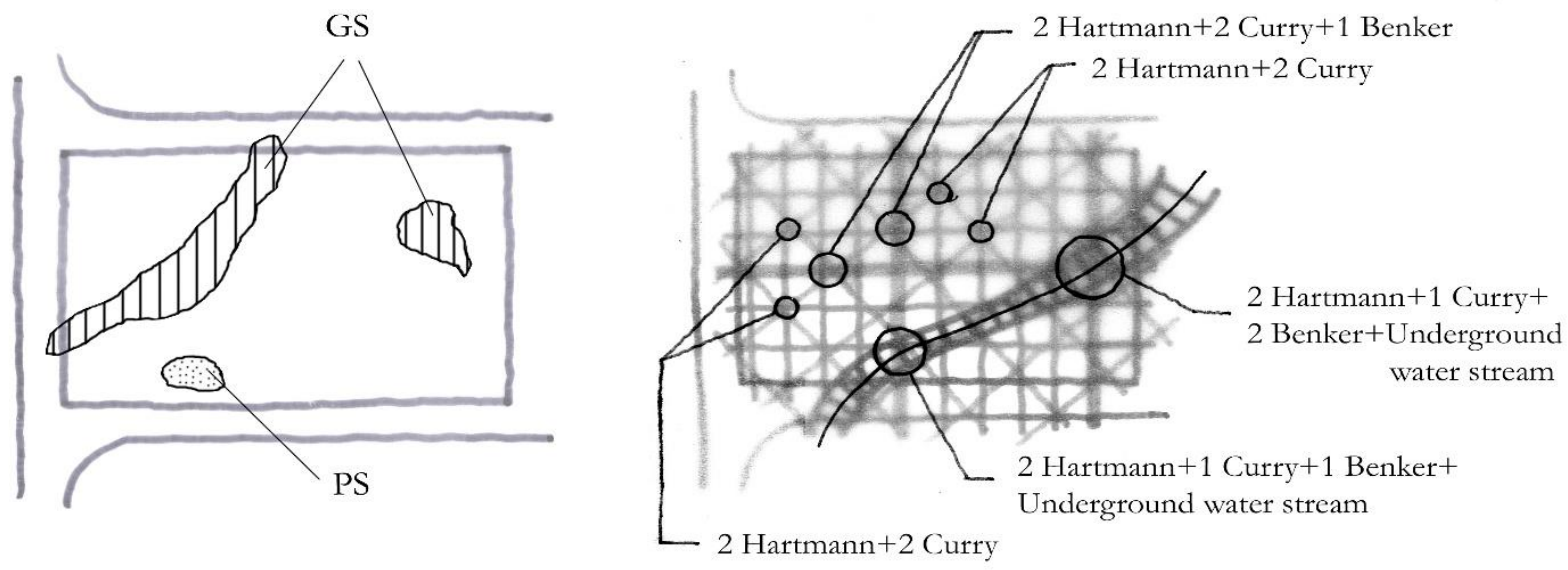

Figure-8: Determining on the site the location of Geopathic Stress areas, and identifying the energy gridlines and where they intersect.

\section{Artificial Sources:}

Through site observation, guided by available maps and plans, sources that emanates artificial EMF/R that are on the site or surrounding it, should be identified and located. This includes high voltage and distributing power-lines, Mobile masts antennas, Broadcast towers, and Radars (Figure-9).

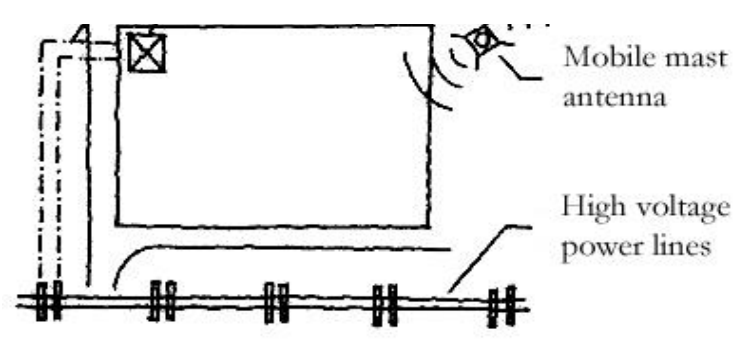

Figure-9: Determining the location of EMF/R sources on site and around the site. 


\subsection{Evaluation}

Natural sources (Requires radiesthesia practitioner knowledgeable about earth energies):

Evaluating the intensity of the detected natural energy fields is also done using radiesthesia tools, as reflected in the force in which the measuring tool is moving. The stronger the motion, the higher the energy field intensity. In case of using the pendulum with geopathic stress (GS) areas, neutral zones imply pendulum rotating in a clockwise direction (Positive polarity) or swinging without rotation, but in case the measuring interfered with a geopathic stress zone, the rotation would clockwise (negative
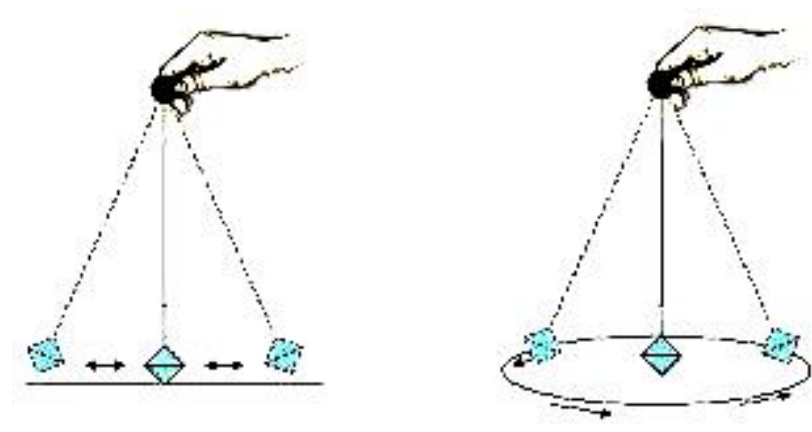
become antipolarity).

Figure-10: Direction of pendulum rotation and it's speed indicate the earth energy quality of being positive or negative and it's intensity.

\section{Artificial Sources:}

There are two steps for evaluating the EMF/R in urban spaces. However, they depend on scale of area addressed. In case of city- wide scale, it would be enough to only acknowledge the emission intensity and range of existing sources (technical information available in concerned institutions and manufactures). In case of a site with ability to survey, an additional step should be implemented to measure the EMF/R intensity using electro-smog meters (Figure 11 and 12). This is needed to identify zones that could have higher radiation intensity, affected by the interference between $\mathrm{EMF} / \mathrm{R}$ of several sources.

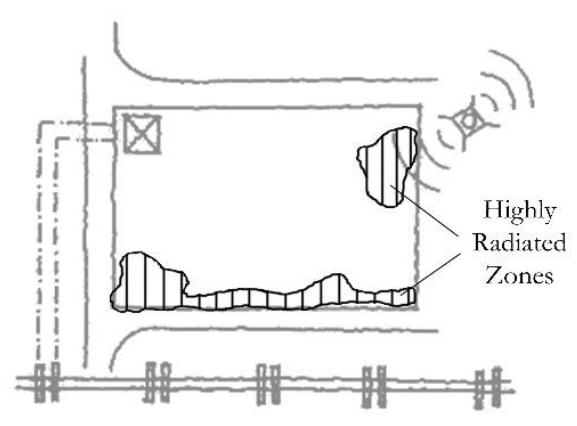

Figure-11: Detecting highly radiated zones

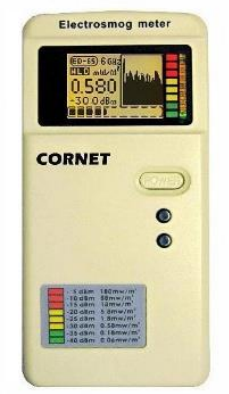

Figure-12: Electrosmog Meter 


\section{GUIDELINES FOR ENVRIONMENTAL URBAN DESIGN}

This section will briefly explain three of the BioGeometrical design methods to generate BG3, to which is most suitable, applicable and flexible for form/space urban design.

\section{1- BioGeometry Qualitative Harmonics}

This method is based primarily on establishing a certain order of space dimensions, according to a sequential series of numerical values, which could presumably engender BG3 energy field quality. They are $(16,19,28,34,43,54,68,72,83,89, \& 99)$. They can be applied on numerical relations between different dimensions, proportions, ratios, angles, or objects, either in space design or crafting of any physical shape/object [3].

\section{2- BioGeometry Motion in Design}

This method is applicable on any element in a motional state (a walking person, a moving vehicle, a water stream, air current, sound and even light waves) as long as this motion is bound within a space with defined boundaries [3]. Figure 12 shows how the motion is classified into four energy qualities, referred as "The BioGeometry Energy Key". The starting point, the linear direction, and two other subqualities generated below the leading motion in clock and anti clock direction (360 degree). The BG3 energy quality is generated when the clock and anti-clock energy qualities (EQ3 \& EQ4) are equal, when obtained; the movable

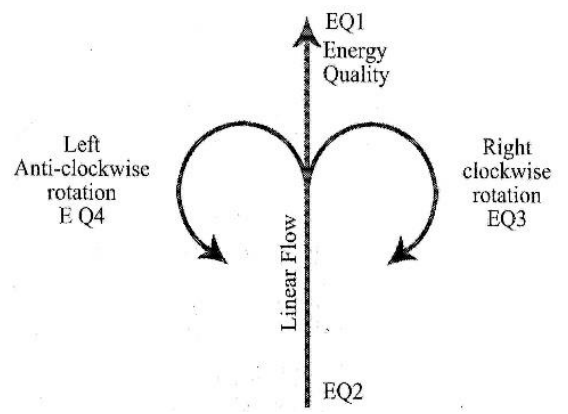

Figure-13: The BioGeometry Energy Key element is in equal distance from the space boundaries.

\section{3- BioGeometry Design Principles}

Four design principles (shifting - rotation - interfacing - transparency) aims for identification of specific distinctive nodes, point locations in the targeted space or virtual centers, in which BG3 is generated and intensified. BioGeometry application research has indicated that geometrical configuration that identifies these virtual centers, do contain BG3 energy quality [3].
Rotation
Shifting
Interfacing
Transparency
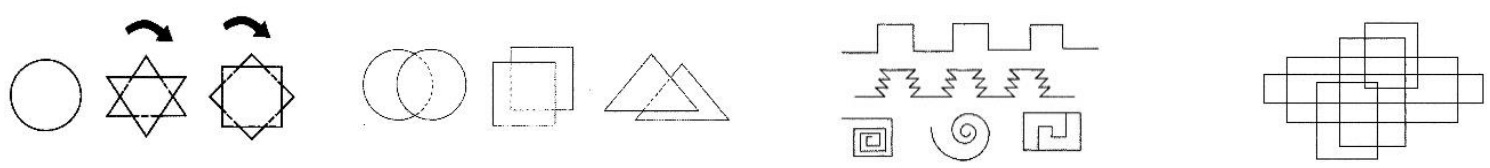

Figure-14: The four BioGeometry Design Principles 
The following section aims to show the applicability of utilizing three BioGeometry design methods in the design of urban spaces through illustrative models featuring different macro and micro urban forms.

\section{Urban Structure - Building Architecture - Streetscape \& Landscape}

Streets are physical forms that circulate different functions in urban spaces, but also it shape and affect (magnify, reduce, ameliorate) subtle or invisible energy flows and qualities. An effective BG design concept could enhance their role in circulating BG3 within city spaces. For example, Squares and roundabouts have the highest amount of roads/streets connected to them. Accordingly, the more squares or a roundabouts located on a PS, the more natural BG3 flows into many spaces/areas in the city (Figure-15). Within the same context, as vehicles provide for the most organized and predictable motions and flows in city

Figure-15: City roundabouts or squares located on PS to

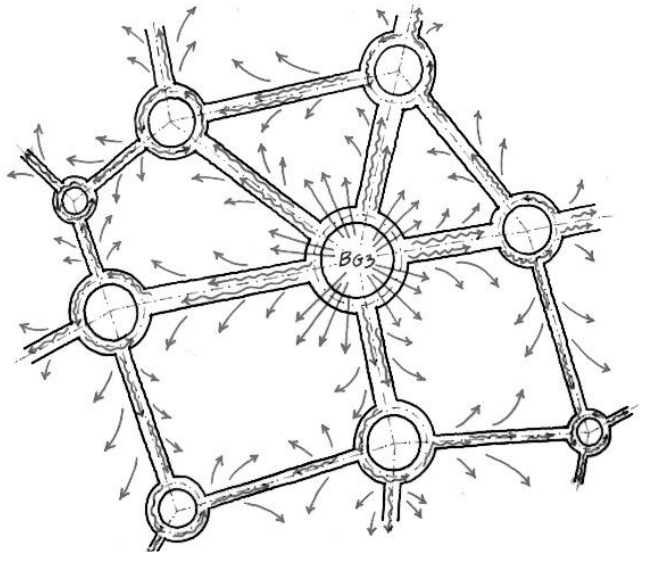
distribute the BG3 energy quality throughout the city spaces, especially in street canyons, then the BioGeometrical method of Motion in Design can be utilized to achieve BG3 energy quality. For example, having the street central axis at equivalent distance from the vertical surfaces of bordering buildings at the two sides, allow for generating a balanced energy key, in congruence with motion of vehicles (Figure-16).
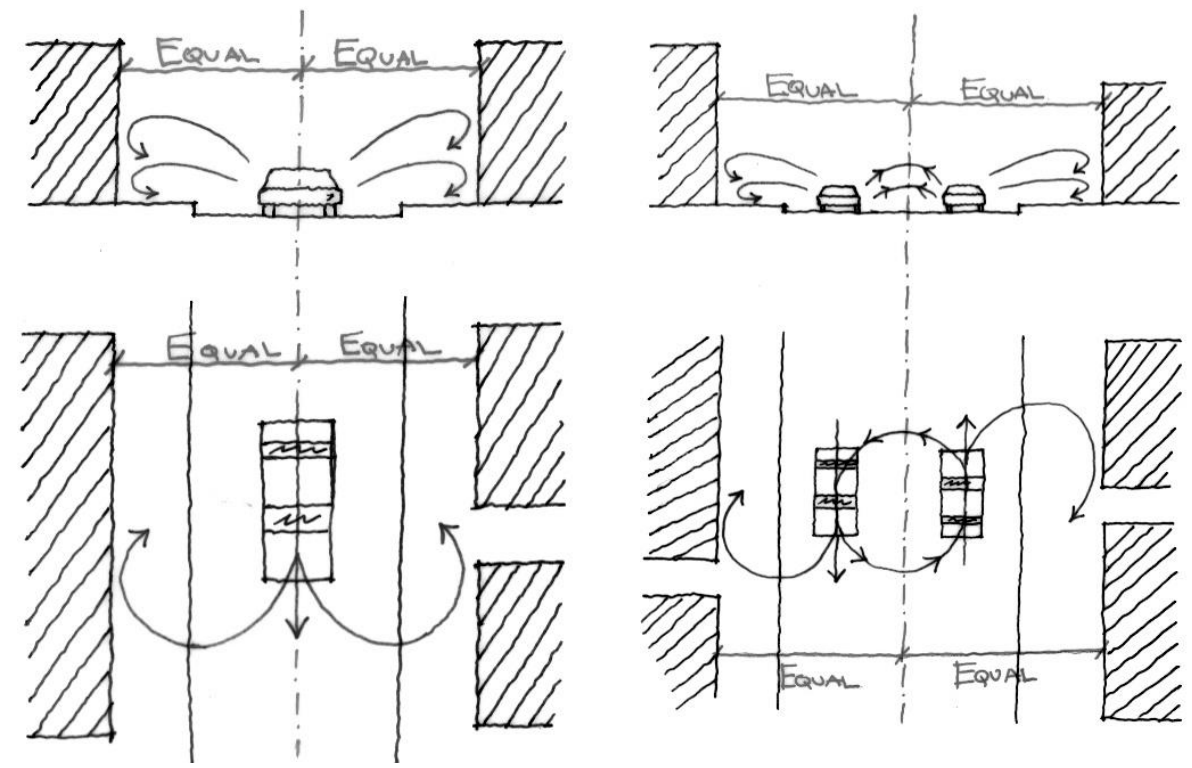

Figure-16: The street width and the car movement can contribute in creating BG3 energy quality within the street. 
Buildings forms are the primary component of the physical structure of cities. They comprise the major image of city's morphology. Generating BG3 energy quality within this context could be attained by appropriating and fitting their height and width proportions to the BioGeometrical numerical paradigm $(1: 1.6 / 1: 1.9 / 1: 2.8 /$ 1:3.4 / 1:4.3 / 1:5.4 / 1:6.8 / 1:7.2 / 1:8.5 / 1:8.9 / 1:9.9).

These proportions could be used in dimensions of buildings (horizontal plans or heights), spacing between them, open and closed spaces. This could further extend to the architecture details, as well as with other elements and components of streetscape and landscape (Figure-17 and 18).

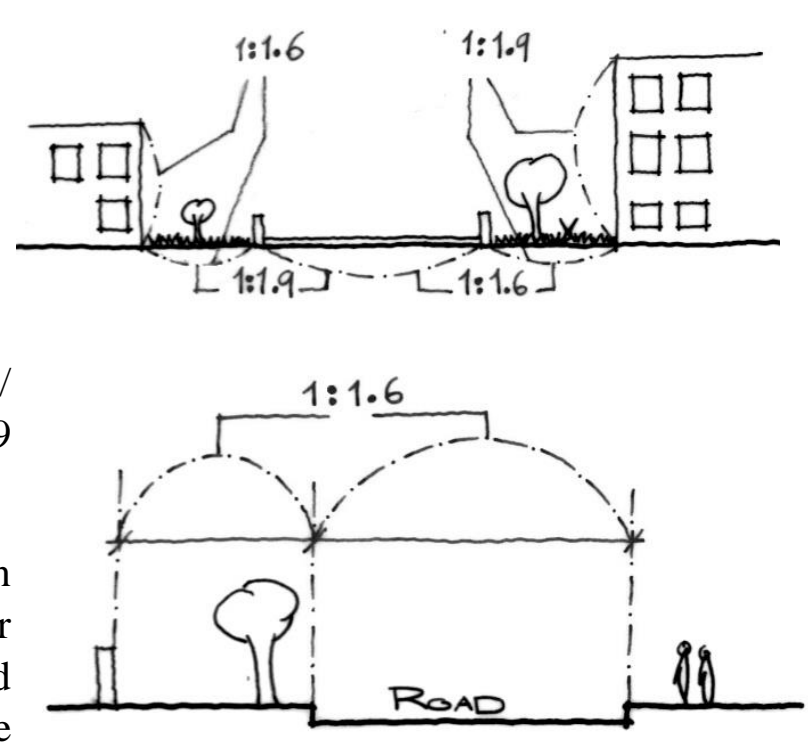

Figure-17: Utilizing the BioGeometry Qualitative Harmonics method in the proportion ratio across the different urban masses, from building heights, to horizontal surfaces and clearances.

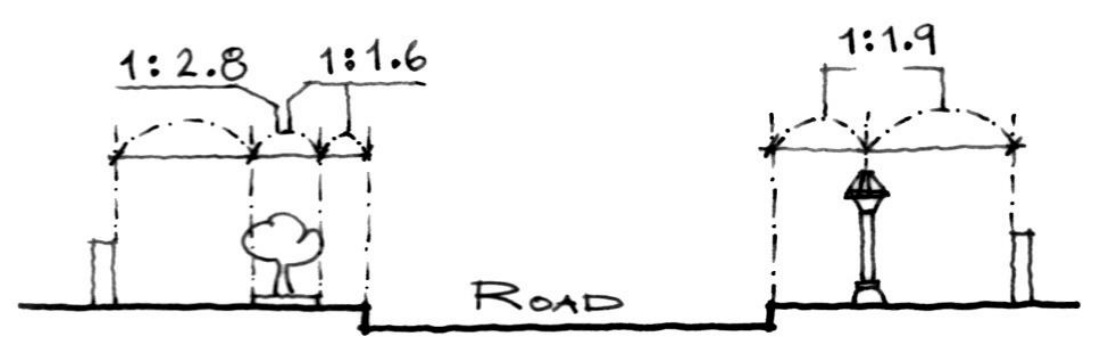

Figure-18: Utilizing the BioGeometry Qualitative Harmonics method in the clearance ratio between the streetscape elements.

With reference to the BioGeometrical design method of Qualitative Harmonics $(\mathrm{BQH})$, there are specific arrangements that generate BG3 energy quality, based on relation between certain amount of objects and their location to each other. However, with a condition that all objects have identical features. If a building form would be duplicated in an urban neighborhood, diverse alternative arrangements (all fit well with design needs) can be examined to identify the one that generate BG3 energy quality.
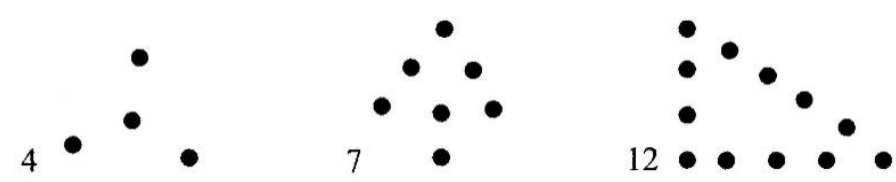

Figure-19: The arrangement of an object for the quantity of $(4,7, \& 12)$. Each creates the BG3 energy quality. 


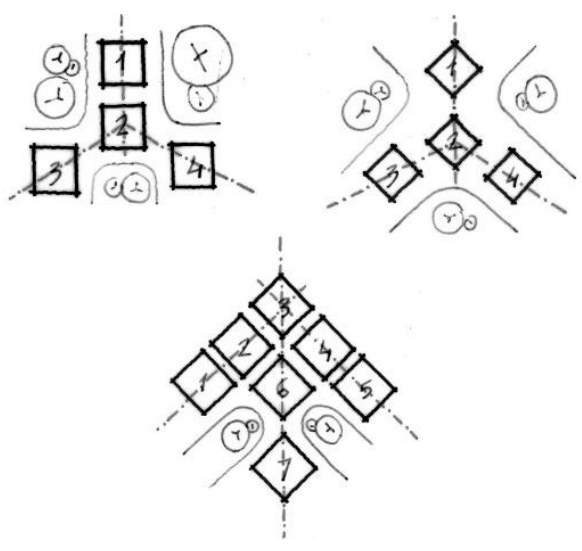

There are three different arrangements that are found to generate BG3 energy for the quantity of 4,7 , and 12 of identical forms/objects (Figure-19) [3]. They can be utilized in different scales, such as arranging a group of buildings, outdoor benches, or other elements that have the same design features (Figure-20 and 21). Radiesthesia measurements should be used in such cases - on scaled drawings or micro models - for mutual verification of targeted results.

Figure-20: BG3 arrangement of 4 \& 7 for identical buildings to create the BG3 energy quality in the urban environment.
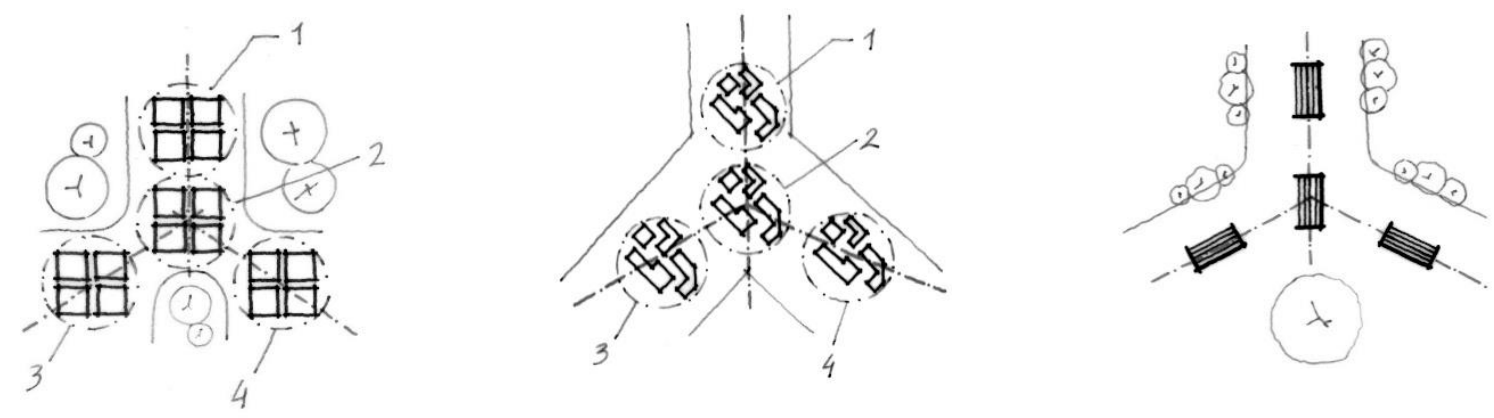

Figure-21: BG3 arrangement of 4 \& 7 for a group of identical buildings forming 1 unit, or arranging the landscane element. to create the RG3 energv dualitv in the urhan envirnnment.

Identifying and featuring virtual centers, is one of the approaches of generating BG3 energy quality, which could be attained through selected orientation of physical paths/lines [3]. This is well illustrated by an application, designed by Dr. Karim (Figure 21) that imply featuring the virtual center in a semi-circle - with two attached lines linked to the center, BG3 is transferred outwardly (Figure-22). Applying this concept in the design of outdoor elements such as a bench, a fountain or a bus stop, can enhance emitting BG3 outwardly to surrounding environment. Generated BG3 becomes intensively magnified when Qualitative Harmonic proportions is also involved in the design $(1: 1.6,1: 1.9$, $1: 2.8$, and more).

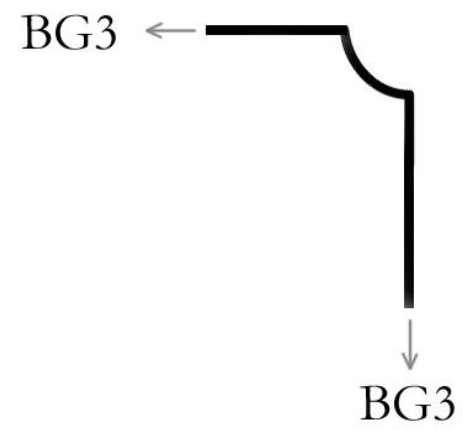

Figure-22: BG3 attained from the virtual center and distributed by the straight lines connected.

JAUES, 17, 62, 2022 
In figure 23, a design example of a fountain showing the rotational form which applies the BioGeometry Design Principles (BDP) method, and the duplicated identical triangle shape that has a total count of 16 , is appling the BioGeometry Qualitative Harmonics method (BQH). Also the ratio proportions between the different heights and width of the form is adding another implementation for the $\mathrm{BQH}$ method. In figure 24 , and example of arranging a landscape pattern made of different shapes to create a rotational form around a BG3 center. This applied the BioGeometry Design Principles (BDP) method.

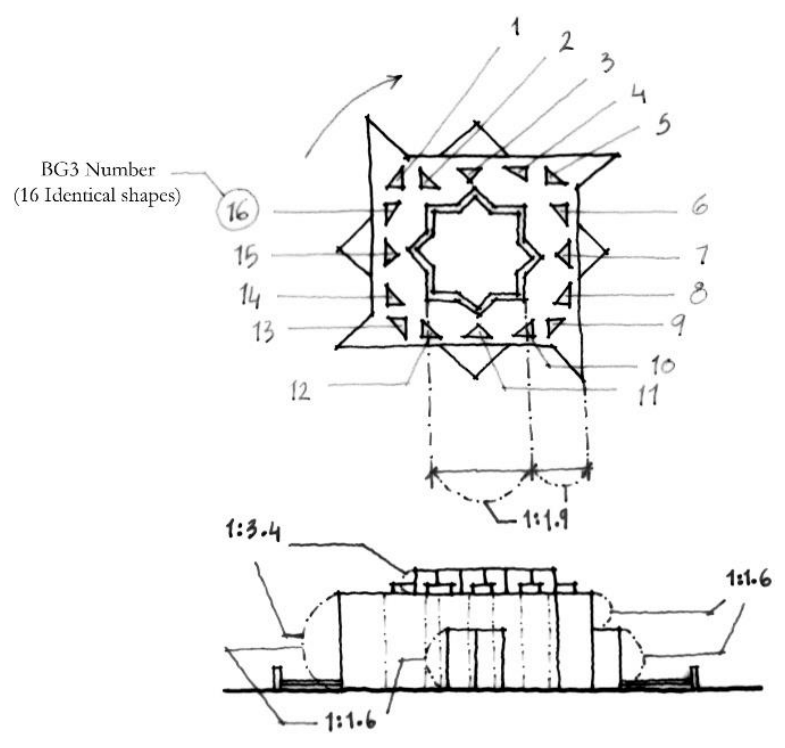

Figure-23: Fountain design applying the BDP \& BQH design methods.

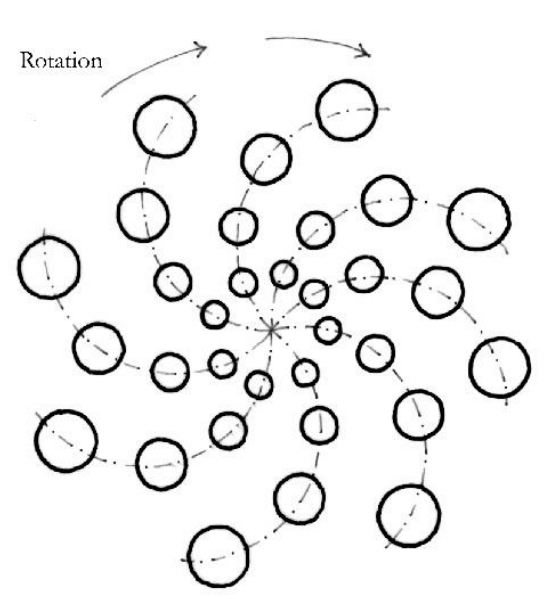

Figure-24: A landscape pattern applying the BDP design method for rotation.

In figure 25, a design example of a bus stop station showing the application of the BioGeometry Design Principles (BDP) method, by creating a BG3 center from the top corner of the bus station, and distributing the BG3 energy quality from the horizontal straight roof, and from the vertical back structure. In addition to applying the BioGeometry Qualitative Harmonics method $(\mathrm{BQH})$ through the proportions of the station forms.

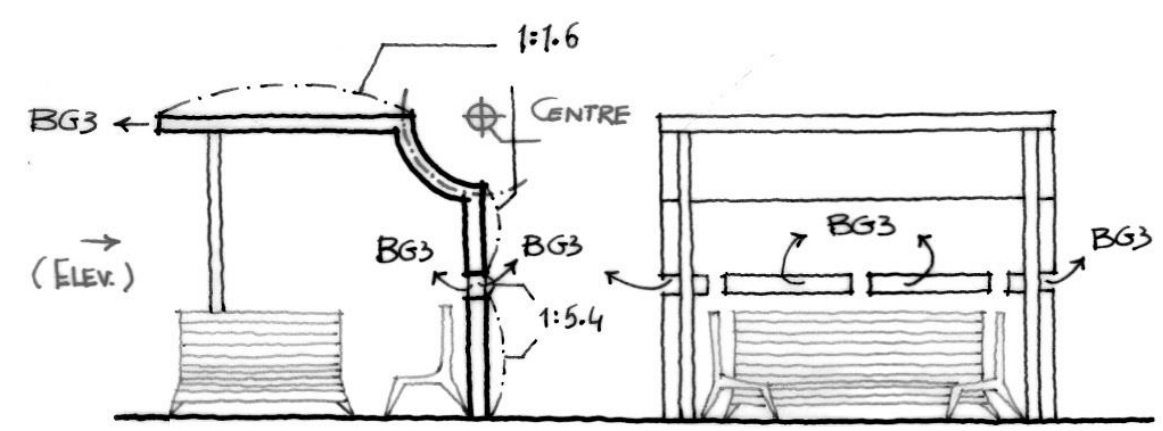

Figure-25: A design for a bus station applying the BDP \& BQH design methods.

In figure 26, a design example of an outdoor bench showing the application of the BioGeometry Design Principles (BDP) method, by creating a BG3 center from the bottom corner of the bench, 
and distributing the BG3 energy quality from the horizontal straight base, and from the vertical back support. The BDP method is applied again from creating multiple BG3 centers along the "Interface" at the top of the bench's back support. In addition to applying the BioGeometry Qualitative Harmonics method (BQH) through the proportions of the bench's forms.

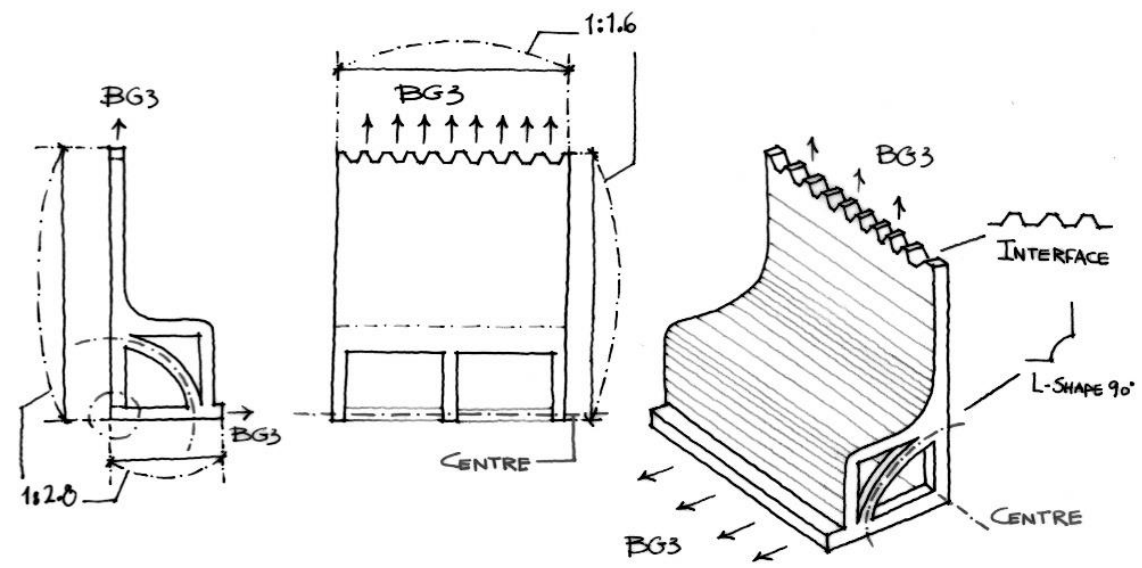

Figure-26: A design for a bus station applying the BDP \& BQH design methods.

\section{SUMMARY AND CONCLUSIONS}

This paper discussed and explored the urban environment through the lens of "Electromagnetic Fields and Radiation" (EMF/R). It highlighted that EMF/R is not just a product of our electricity use or the wireless technologies, but rather a fundamental component of all matter in the universe. Accordingly, all living beings including humans, animals and plants are "Electromagnetic Beings". The question that the paper highlights, is whether the EMF/R that is used by our modern technologies have an impact on human health and wellbeing? From a theoretical point of view, it surely have an impact because electromagnetic waves "interferes" and can change the quality of one another. From a practical and experimental point of view, there has been a lot of studies indicating there is an impact - in fact a negative one on the human health due to exposure to EMF/R from sources such as electric power lines, transformers, radars, and mobile mast antennas. However, the scientific community has been ignoring this issue because the short term impact is not vivid enough, and the long term requires time to be identified. But this fails to address the issue, as EMF/R technologies are in constant increase and without sufficient protective measures, therefore increasing the risks of more health problems globally.

Given the theoretical credibility that EMF/R are negatively impacting the human health and well-being, this paper brought attention to the mitigation and design trends that addresses these issues. First by addressing EMF/R in our urban environment from artificial sources, and second is $\mathrm{EMF} / \mathrm{R}$ from natural sources. The paper presented measuring and detection techniques, and also mitigation and amplifying methods through the application of the science of BioGeometry in the design of the urban environment. Among the different BioGeometry application methods, 
some of them were presented and applicable to implement in the design of urban spaces. A step by step guideline has been developed along with illustrative models to showcase the design possibilities in the future

The illustrative models have high potentials of application on a very wide and divest range of urban planning and design processes. They can well serve the purpose of a general guidelines document that compile selected Biogeometry design techniques that eventually aims to enhance positive impacts on human health, environmental and ecological balance, and overall quality of life.

Increasing knowledge of negative impacts of different electromagnetic sources in our urban spaces implies new critical challenges. An environmentally sound and healthy city is now a global vision that aims to correct past mistakes. This new shift in the paradigm of urban and environmental planning requires a wider scale of environmental awareness, and a larger scale of developing new areas of scientific interdisciplinary research. The same strongly applies - and in conjunction to disciplines of electromagnetism and human pathology - to disciplines of urban and environmental planning, urban and architectural design, and other related disciplines such as human and human organisms ecology. Deep and authentic recognition and approval of the effect of electromagnetic features in our surrounding environment is a real opportunity toward major shifts in the paradigms of above mentioned disciplines. Such shifts open new and wide vistas for planning, designing and managing much better and environmentally sound cities that have magnificent harmony with both nature and technological spheres, harnessing and utilizing their positive forces and returns and averting and evading their negative aspects.

1. Wout, J., Frei, P., Roösli, M., Thuróczy, G., Gajsek, P., Trcek, T., Bolte, J., Vermeeren, G., Mohler, E., Juhász, P., Finta, V., Martens, L., 2010, Comparison of personal radio frequency electromagnetic field exposure in different urban areas across Europe. Environmental Research 110(7), 658-663.

2. Greene, B., 2000, The Elegant Universe, Vintage Books, March 2000, pp.136-139, New York, USA.

3. Karim, I., 2010, Back To A Future For Mankind, BioGeometry Consulting Ltd, March 2010, Egypt, ISBN: 978-977-6232-01-3.

4. World Health Organization, June 2011, Electromagnetic fields and public health: mobile phones, website, www.who.int/peh-emf/en, August 2014.

5. Pearson C., 2018, "The effects of Electromagnetic Fields in the workplace", BSRIA, https://www.designingbuildings.co.uk/wiki/The_effects_of_electromagnetic_fields_in _the_workplace.

6. Office Essentials Checklist, 2005, website, https://www.entrepreneur.com/article/81952.

7. Sivani, S., and Surdarsanan, D., 2013, "Impacts of radio-frequency electromagnetic field (RFEMF) from cell phone towers and wireless devices on biosystem and ecosystem", www.biolmedonline.com, Vol. 4, Issue 4, Jan 2013, p.203. 
8. Office of Spectrum Management, 2003, "United States Frequency Allocations-The Radio Spectrum", U.S Department of Commerce, National Telecommunications and Information Administration NTIA, Oct 2003, www.ntia.doc.gov.

9. Learn Genetics, 2013, The Inside Story Of Cell Communication, The University of Utahwww.learn.genetics.utah.edu, April 2013.

10. Cherry, N., 2001, "Evidence that Electromagnetic fields from high voltage power lines and in buildings, are hazardous to human health, especially to young children", Lincoln UniversityNew Zealand, April 2001.

11. Kliukiene, J., Tynes, T., and Andersen, A., 2003, "Residential and Occupational Exposures to 50$\mathrm{Hz}$ Magnetic Fields and Breast Cancer in Women: A Population-based Study", American Journal of Epidemiology, Vol. 159, No. 9, 2003.

12. Gittleman, A.L., 2010, Zapped, HaperOne, 2010, New York, USA, p.31, 44, 132.

13. Milham, S., and Morgan, L.L., 2008, "A New Electromagnetic Exposure Metric: High Frequency Voltage Transients Associated With Increased Cancer Incidence in Teachers in a California School", American Journal Of Industrial Medicine, 2008.

14. Lai, H., and Singh, N.P., 1997, "Acute Exposure to a $60 \mathrm{~Hz}$ Magnetic Field Increases DNA Strand Breaks in Rat Brain Cells", University of Washington, Bioelectromagnetics, Vol. 18, No. 2, 1997, pp.156-165.

15. Havas, M., 2004, "Chapter 10-Biological Effects of Low Frequency Electromagnetic Fields", Electromagnetic Envrionments and Health in Buildings, www.magdahavas.org, April 2013.

16. Levitt, B.B., and Lai, H., 2010, "Biological effects from exposure to electromagnetic radiation emitted by cell tower base stations and other antenna arrays", NRC Researchwww.nrcresearchpress.com, Environ. Rev. Vol. 18.

17. Tofani, S., Agnesod, G., Ossola, P., Ferrini, S., and Bussi, R., 1986, "Effects of Continuous lowlevel exposure to radio-frequency radiation on intrauterine development in rats", Health Phys., Vol. 51, No. 4, 1986, pp.489-499.

18. Balmori, A., 2009, "Electromagnetic pollution from phone masts, Effects on Wildlife", Journal for Intl. Society of Pathophysiology, www.pathophysiologyjournal.com, Vol. 16-Issue 2, 2009.

19. Selga, T., and Selga, M., 1996, Response of Pinus Sylvestris L. needless to electromagnetic fields. Cytological and ultrastructural aspects, Sci. Total Envrion, Vo. 180-Issue, 1996, pp. 6573.

20. Roux, D., Vian, Al., Girad, S., Bonnet, P., Paladian, F., Davies, E., and Ledoigt, G., "High frequency $(900 \mathrm{MHz})$ low amplitude $(5 \mathrm{Vm}-1)$ electromagnetic field: a genuine environmental stimulus that affects transcription, translation, calcium and energy change in tomato", Planta Online, Vol. 227, No. 4, 2007, pp.883-891.

21. Thomas, T., Nov 2009, As new evidence links mobile phones to a greater risks of tumours, could using one cost your child their life?, website, www.dailymail.co.uk, April 2013. 
22. Regan, K., March 2006, New Study Revives Old Debate About Cell Phone and Brain Tumors, www.technewsworld.com, April 2013.

23. Agarwal, A., Deepinder, F., Sharma, R.K., Ranga, G., and Li, J., 2008a, "Effect of cell phone usage on semen analysis in men attending infertility clinic: an observational study", PUBMEDwww.ncbi.nlm.gov, Vol. 89, No. 1, Jan 2008.

24. Horseva, N., Grigoriev, Y., and Gorbunova, N., 2011, "Psychophysiological Characteristics of Children Cell Phone Users. Results of 4-Year Monitoring", Radiation Biology. Radioecology, 2011, Vol. 51, No. 5, pp.617-623.

25. Hacker, G.W., Eder, A., Augner, C., and Pauser, G., 2005, "Geopathic Stress Zones and Their Influence on the Human Organism", http://www.med-grenzfragen.eu, April 2013.

26. Thurnell-Read, J., 2006, Geopathic Stress \& Subtle Energy, Life-Work Potential LWP, 2006, UK, p.3.

27. Gerhard, W.H., Pawlak, E., Pauser, G., Tichy, G., Jell, H., Posch, G., Kraibacher, G., Aigner, A., and Hutter, J., 2005, "Biomedical Evidence of Influence of Geopathic Zones on the Human Body: Scientifically Traceable Effects and Ways of Harmonization", Forsch Komplementärmed Klass Naturheilkd, Vol. 12, No. 6, Dec 2005.

28. Creightmore, R., 2007, Geopathic Stress, website, April 2013, http://www.landandspirit.net www.helios3.com.

29. Maby, J.C., 1993, The Physics of the Divining Rod, G.Bell \& sons London, 1993.

30. Dharmadhikari, N.P., Rao, A.P., Pimplikar, S.S., Kharat, A.G., Aghav, S.D., Meshram, D.C., Kulkarni, S.D., and Jain, B.B., 2010, "Effect of geopathic stress on human heart rate and blood pressure", Indian Journal of Science and Technology, Vol. 3, No. 1, Jan 2010.

31. Banis, U., 2013, WHAT IMPACT DOES GEOPATHIC STRESS HAVE ON HEALTH AND WELLBEING?, www.geopathology.com, April 2013.

32. Shah, S., May 2012, Geopathic Stress Symptoms, website, April 2013, http://www.freeastrovastutips.com/page/8.

33. Brown, E., 2012, Geopathic Stress, website, April 2013, http://www.gentlepowers.com.

34. Riggs, R., 2013, Understanding Geopathic Stress \& Electromagnetic Stress, website, April 2013, www.royriggs.co.uk.

35. Gordon, R., 2010, Book Review: Are You Sleeping in a Safe Place?, www.thenaturalrecoveryplan.com, March 2013.

36. Ancient-Wisdom, website, http://www.ancient-wisdom.co.uk/leylines.htm, Dec 2012.

37. Environics, 2012, WHAT ARE RADIATION, website, April 2013, http://www.environics.co.in/radiation.html.

38. Atnip, M., Radiesthesia, website, April 2013, www.ephrataministries.org.

39. Gardner, M., 1957, FADS AND FALLACIES, 2nd edition, Dover Publications, Inc., New York. 
40. The Guardian, Nov 2007, Extra Curricular-Dowsing can reveal a hidden world under our feet, www.guardian.co.uk, April 2013.

41. BBC News, Sept 2010, "Using the energies of the Earth in Guernsey", www.news.bbc.co.uk, April 2013.

42. Pendulum Dowsing, Radiesthesia and Water Diving, 2006, website, www.ephesians-511.net, Feb 2013.

43. BBC News, May 2006, "Divining rods help beat drought", website, April 2013, www.news.bbc.co.uk.

44. GIBB Information Organization for Building Biology, 2004, "Harmonization with BioGeometry", Dar El Taawon Association For Printing and Publishing, 2004.

45. Zweili, C., Oct 2003, Karim aus dem wunderland?, Tagblatt Online- www.tagblatt.ch, April 2013.

46. Sharaf N., et al, Role of Designed Bio-Geometrical Forms in Antagonizing Neurobehavioral Burden of Wi-Fi Radiation: Evidence-Based Experimental Study, Biomedical \& Pharmacology Journal, September 2019, Vol. 12(3), p. 1217-1234.

47. Sharaf E., et al, Protective Role of BioGeometry Against Indoor Pollutants of Some Egyptian Building Materials in Adult Male Rats, World Journal of Medical Sciences 10 (3): 337-346, 2014, DOI: 10.5829/idosi.wjms.2014.10.3.1142.

48. Karim, I., Scientific Validation of BioGeometry, web site, April 2013, www.biogeometry.com.

49. Gilbert, R.J., The Hidden Energy Science of Sacred Geometry, Institute for Holistic Studies, www.vesica.org, April 2013.

50. Howeidy, D., 2013, "A Design Approach Using Bio-Geometry in the Interior Architectural Spaces With Reference to Heal Attention Deficit Hyperactivity Disorder (ADHD)", PhD Thesis, Faculty of Engineering, Cairo Univ., Egypt.

51. Maley, M.J., Creating Healthy Spaces: BioGeometry and the Creation of Optimal Healthy Environments, website, April 2013, www.creatinghealthyspaces.com.

52. Toronto Dowser, Essential Foundation: New Discoveries, And Future Project In Canada, web site, April 2013, www.dowsers.info.

53. Deif, A., 2008, "Pi, Phi and the Great Pyramid", Al-Ahram weekly online, Issue No. 890, March/April 2008, Cairo, Egypt.

54. Wafik, A., 2013, "BioGeometry as a Design Tool for Elements in Urban Spaces to Reduce The Harmful Effects of Electromagnetic Fields and Geopathic Stress", Master Thesis, Faculty of Engineering, Cairo Univ., Egypt. 